\title{
Investigation of effect of heat exchanger size on power output in low-temperature difference Stirling engines
}

\author{
Linda Hasanovich ${ }^{1}$, and David Nobes ${ }^{1 *}$ \\ ${ }^{1}$ University of Alberta, Mechanical Engineering Department, 9211116 Street NW, Canada
}

\begin{abstract}
The Stirling engine is capable of converting any source of thermal energy into kinetic energy, which makes it an attractive option for utilizing low-temperature sources such as geothermal or waste heat below $100{ }^{\circ} \mathrm{C}$. However, at these low temperatures, the effects of losses are proportionally higher due to the lower thermal potential available. One such significant loss is excess dead volume, wherein a significant contributor is the heat exchangers. The heat exchangers must be selected to optimize power output by minimizing the dead volume loss while maximizing the heat transfer to and from the engine. To better understand what the optimal geometry of the heat exchanger components is, a Stirling engine is modelled using a third-order commercial modelling software (Sage) and trends of engine properties of power, temperature, and pressure for different heat exchanger geometries are observed. The results indicate that there is an optimum heat exchanger volume and geometry for low temperature Stirling engines. This optimum is also affected by other engine properties, such as regenerator size and engine speed. These results provide insight into the optimal geometry of these components for low-temperature Stirling engines, as well as providing design guidance for future engines to be built.
\end{abstract}

\section{Introduction}

Low temperature heat sources, namely those below $100{ }^{\circ} \mathrm{C}$, are a possible energy source for generating electricity that could lower carbon emissions. For example, in the province of Alberta, Canada, there is a large amount of low temperature geothermal energy [1] and industrial waste heat [2] available to be converted to electricity. Currently these energy sources are not being exploited for electricity generation due to a gap in the available technology. One possible technology solution is the Stirling engine as these have been proven to run at temperature differences as low as $0.5^{\circ} \mathrm{C}$ and source temperatures below $100{ }^{\circ} \mathrm{C}$ [3].

For these low temperature Stirling engines there are proportionally higher losses present than in a high temperature Stirling engine due to the lower thermal potential available, and thus less energy available to overcome losses. This makes minimizing losses in the engine design a priority for low temperature Stirling engines. One significant loss is that of dead volume, which is any volume that is not swept by the pistons. Excessive dead volume is known to reduce the engine power [4] as it reduces the overall cyclic pressure change. A

\footnotetext{
*Corresponding author: dnobes@ualberta.ca
} 
large contributor to dead volume in a Stirling engine is the heat exchanger volume, which is necessary for the thermal exchange to and from the engine working fluid. This presents the need to optimize the heat exchanger volume to maximize the heat transfer into and out of the engine while minimizing the associated losses due to the heat exchanger dead volume. Determining this optimum size is of particular importance for low temperature Stirling engines due to the low thermal potential available.

The effect of heat exchanger size on engine power output will be investigated in this paper using a $3^{\text {rd }}$ order model. The results of this investigation will inform the design of an experimental engine to confirm the model accuracy and the optimal heat exchanger size for the low temperature Stirling engine.

\section{Modelling Approach}

\subsection{Model Choice}

To investigate the effect of heat exchanger size on power output in a Stirling engine, a model is needed that can capture the overlapping processes of the Stirling cycle as well as the effect of improved thermal exchange on engine power. There are several Stirling engine models available, as categorized by Martini [5] according to their complexity and assumptions. While $1^{\text {st }}$ and $2^{\text {nd }}$ order models are simple to use, neither capture the relationship between thermal exchange and dead volume, and their effects on engine power. This is because neither of these classes of models accounts for the change in gas temperature resulting from changes to the heat exchanger volume or shape, as both assume a gas temperature for the engine spaces.

A $3^{\text {rd }}$ order model is chosen to study the relationship between heat exchanger size and power output as it is able to capture the effect of heat exchanger volume on gas temperature and thus engine power. It does this in a spatial and time varying model, where the conservation of energy, mass, and momentum equations and an equation of state are solved numerically.

The $3^{\text {rd }}$ order model that is used is the commercial Stirling engine software Sage created by Gedeon [6]. This has been used for modelling various engines [7] including low temperature Stirling engines [8]. Sage is able to provide information on engine power, gas temperatures, and pressure swing for various heat exchanger sizes.

\subsection{Experimental Engine Information}

For this investigation, the engine modeled is based on an experimental engine currently being designed, of which a model is shown in Fig. 1. This engine is an inline Gamma-type Stirling engine that will run at a source temperature of $95^{\circ} \mathrm{C}$ and a sink temperature of $5{ }^{\circ} \mathrm{C}$. The working fluid is air. The charge pressure will range from atmospheric to a maximum of approximately 10 bar. The power piston stroke will be variable in order to vary the compression ratio. The power piston of this engine is located in the compression space. The heat exchangers and regenerator are externally mounted to the engine body, with connection ports to the displacer cylinder. The engine parameters in this study are approximated based on this experimental engine, and the trends observed in the model results will be used to further inform the design of the engine. 


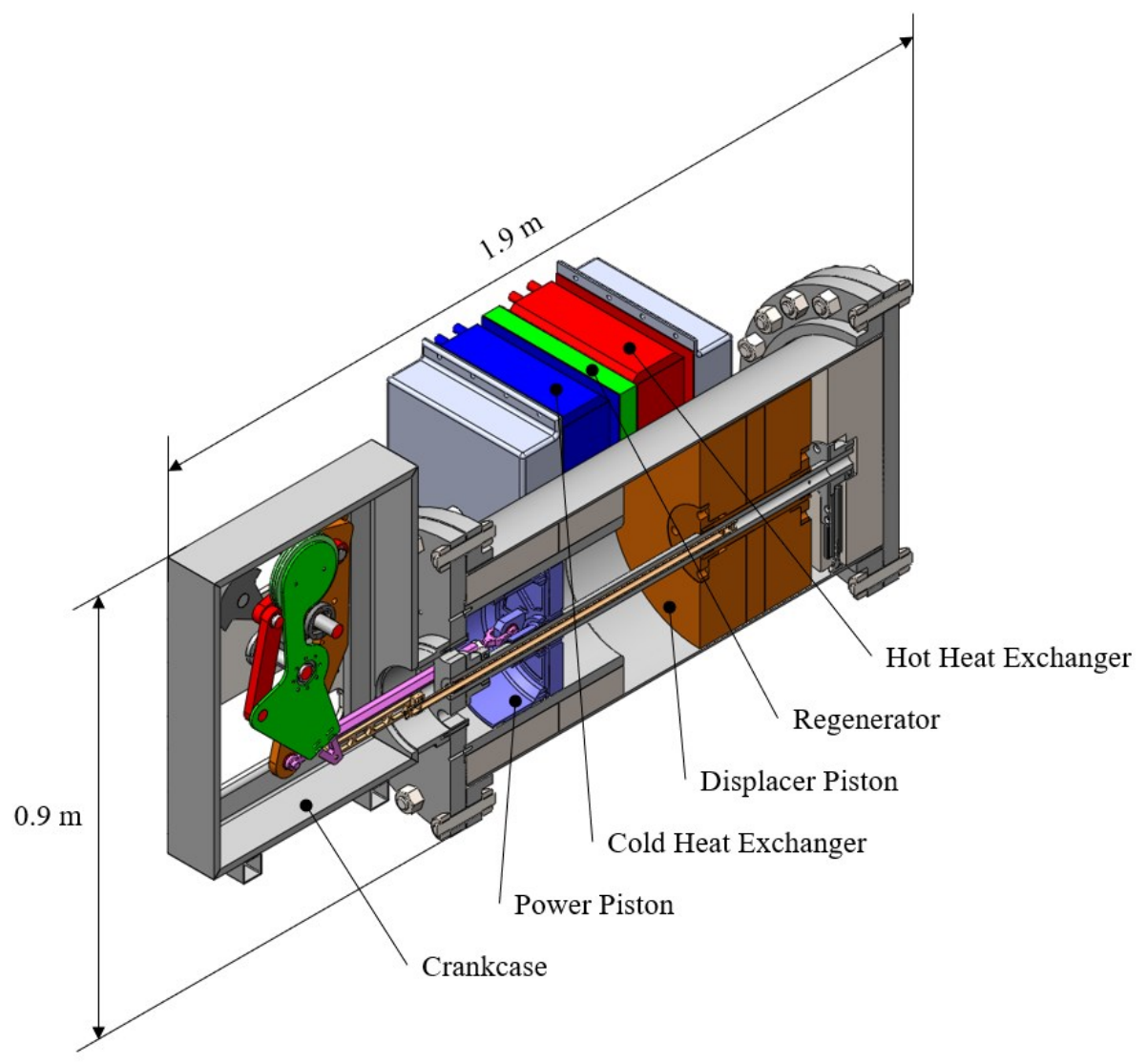

Fig. 1. Section view of the solid model of the experimental engine.

\subsection{Sage Model Setup}

Sage models the Stirling engine as connected components, where the connections act as a common boundary value between the components. The top level Sage model interface including all components is shown in Fig. 2. The engine being modelled is a Gamma-type Stirling engine.

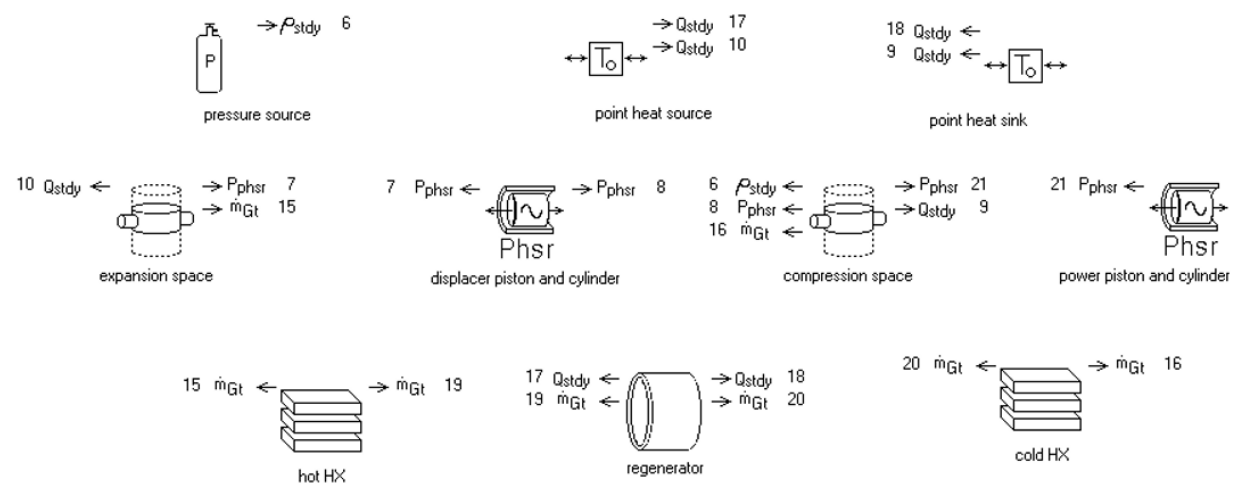

Fig. 2. Top-level Sage model interface showing components used. 
In Fig. 3, the connections between component sub-models is shown. The gas spaces are connected with mass flow connections, while the regenerator and piston walls are connected to the heat source and sink with thermal flows. This is done for model stability. The piston walls are modelled as a thick surface, with heating of the wall due to the gas occurring within a thin layer. This is because the expansion and compression spaces are assumed to be quasiadiabatic. The heat exchangers are not thermally connected to any components as they are assumed to be isothermal. They are modelled as isothermal surfaces in Sage, with the temperatures equal to the source and sink temperatures for the hot and cold heat exchangers respectively. The pressure source is connected to the compression space where the power piston is also connected.

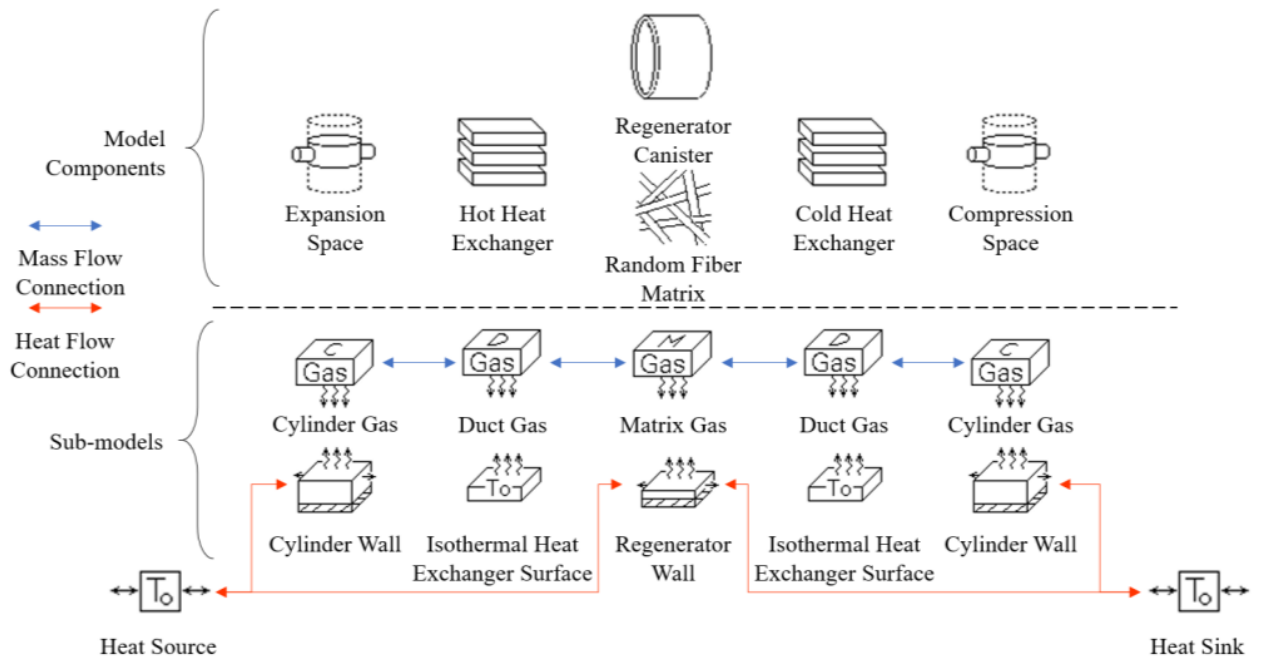

Fig. 3. Diagram of Sage model component connections.

Sage solves the conservation equations on a one-dimensional spatial grid where the number of cells can be set for a given component. For a component where there is a steeper temperature gradient or more fine structures, namely the heat exchangers and regenerator, more spatial cells are used to better capture the spatial variation. The number of spatial cells used for each model component is summarized in Table 1. Sage also solves a temporal solution on a time grid. The number of time nodes used for the temporal solution is set to be 15.

Table 1. Number of spatial cells in Sage model components.

\begin{tabular}{|c|c|}
\hline Model Component & Number of Cells \\
\hline Expansion Space & 3 \\
\hline Displacer Piston and Cylinder & 3 \\
\hline Compression Space & 3 \\
\hline Power Piston and Cylinder & 3 \\
\hline Hot Heat Exchanger & 7 \\
\hline Regenerator & 11 \\
\hline Cold Heat Exchanger & 7 \\
\hline
\end{tabular}


For model simplicity, the working fluid was assumed to be dry air and is represented by the ideal gas law as its temperature and pressure variation is not very high. The motion of the displacer and power piston is modelled as perfectly sinusoidal.

\subsection{Engine Operating Conditions}

The engine operating conditions chosen for this study are chosen based on the experimental engine shown in Fig. 1. A summary of engine properties that are held fixed in the model is provided in Table 2 .

Table 2. Fixed engine properties.

\begin{tabular}{|c|c|}
\hline Engine Property & Value \\
\hline Charge Pressure & $101.325 \mathrm{kPa}$ \\
\hline Hot Side Temperature & $368.2 \mathrm{~K}$ \\
\hline Cold Side Temperature & $278.2 \mathrm{~K}$ \\
\hline Displacer Piston Diameter & $0.35 \mathrm{~m}$ \\
\hline Displacer Piston Stroke & $0.20 \mathrm{~m}$ \\
\hline Power Piston Diameter & $0.30 \mathrm{~m}$ \\
\hline Power Piston Stroke & $0.30 \mathrm{~m}$ \\
\hline Regenerator Porosity & 0.95 \\
\hline Regenerator Wire Diameter & $0.00005 \mathrm{~m}$ \\
\hline Regenerator Type & Random Fiber Matrix \\
\hline Heat Exchanger Channel Width & $0.0015 \mathrm{~m}$ \\
\hline Heat Exchanger Channel Height & $0.0060 \mathrm{~m}$ \\
\hline
\end{tabular}

The charge pressure is chosen to be atmospheric pressure as the experimental engine is designed to run at atmospheric pressure. The hot and cold side temperatures are chosen to be $95^{\circ} \mathrm{C}$ and $5^{\circ} \mathrm{C}$ respectively. The hot side is chosen as low temperature heat sources can be found below $100^{\circ} \mathrm{C}$. The cold side temperature is chosen based on the average yearly temperature in Edmonton, Alberta [9], for which the engine is being designed. The engine speed chosen as the basis is $1 \mathrm{~Hz}$. This speed is chosen based on an empirical relation by Kolin [3] for a loaded Stirling engine, as well as experimental data for the maximum power of another low temperature Gamma-type Stirling engine [10]. In a real Stirling engine, the engine speed varies depending on the loading of the engine. In Sage, the engine speed must be prescribed and the power output may vary with engine speed. Due to this, a sensitivity on the effect of engine speed is performed, as summarized in Table 3. 
Table 3. Sensitivities performed on selected engine properties.

\begin{tabular}{|c|c|c|c|}
\hline Engine Property & Base Value & Low Value & High Value \\
\hline Engine Speed & $1 \mathrm{~Hz}$ & $0.5 \mathrm{~Hz}$ & $2 \mathrm{~Hz}$ \\
\hline Regenerator Diameter & $0.20 \mathrm{~m}$ & $0.15 \mathrm{~m}$ & $0.25 \mathrm{~m}$ \\
\hline Regenerator Length & $0.10 \mathrm{~m}$ & $0.05 \mathrm{~m}$ & $0.15 \mathrm{~m}$ \\
\hline
\end{tabular}

\subsection{Engine Geometry}

The engine geometry being modelled in Sage is based on a planned experimental engine, as shown in Fig. 1, that will be used to verify the results of the model. This engine is primarily made from steel, so the built-in stainless steel material in Sage (SS304) is used for all the components. The power piston and displacer piston are phased $90^{\circ}$ apart, as this phase difference has been shown to be optimal for Gamma-type Stirling engines [10]. This is further justified by Senft, who has shown that engine power output is not very sensitive to phase angle [11]. The power piston is connected to the compression space. The fixed engine geometric dimensions are summarized in Table 2.

The piston diameters and strokes used were based on the experimental engine being designed. The displacer piston stroke volume is targeted to be approximately $40 \mathrm{~L}$. The compression ratio of the engine ranges from approximately 1.1 to 1.9 in this study in order to cover a wide range of values. This range also includes the range of empirically calculated estimates of optimal compression ratio. The Egas [12] estimate calculated using equation (1) is 1.3 and the Kolin [3] estimate calculated using equation (2) is 1.1. For both of these estimates the source and sink temperatures are used for $T_{\text {hot }}$ and $T_{\text {cold }}$ respectively.

$$
\begin{gathered}
C R=\frac{T_{h o t}}{T_{\text {cold }}} \\
C R=1+\frac{T_{h o t}-T_{\text {cold }}}{1100}
\end{gathered}
$$

The regenerator size was informed by an analytical calculation of the mass of regenerator material required to store the energy contained in the mass of air in the engine piston spaces without allowing a large change in the regenerator material temperature. A smaller temperature change in the regenerator material is desirable as it makes the thermal storage process near reversible. This estimate would correspond to a scenario where there are no heat exchangers and the regenerator must store all of the energy in the cycle.

The amount of energy in the mass of air in the piston spaces is found using:

$$
Q=m_{\text {air }} c_{p, a i r}\left(T_{\text {hot }}-T_{\text {cold }}\right)
$$

where $Q$ is the total energy in the air in Joules, $m_{\text {air }}$ is the total mass of air in kilograms, and $c_{\mathrm{p} \text {,air }}$ is the specific heat capacity taken at the average air temperature in Joules per kilogram per Kelvin.

The mass of regenerator material is then found by equating the energy of air in the engine and rearranging the specific heat equation to solve for mass, as:

$$
m_{\text {reg }}=\frac{Q}{C_{p, r e g}\left(T_{\text {hot }, \text { reg }}-T_{\text {cold,reg }}\right)}
$$


where $c_{\text {p,reg }}$ is the specific heat of the regenerator material. $T_{\text {hot,reg }}$ and $T_{\text {cold,reg }}$ are the allowable hot and cold regenerator temperatures. In this case, the change in temperature in the regenerator material is limited to within $5{ }^{\circ} \mathrm{C}$ of the average air temperature, making the values $55^{\circ} \mathrm{C}$ and $45^{\circ} \mathrm{C}$ respectively.

The total volume of the regenerator is found using the density of the regenerator material (SS304) to determine the solid volume and then using the porosity to determine the overall volume. The porosity, defined as the void volume over total volume, was chosen to be 0.95 based on experimental engines with random fiber matrices regenerator types [13], and to lower the overall pressure drop through the regenerator. The regenerator wire size is representative of the thickness of wire in steel wool [14], which is the type of material that would be used for this regenerator.

For a regenerator length equal to that of the shortest heat exchanger length, $0.1 \mathrm{~m}$, the calculated overall diameter is $0.16 \mathrm{~m}$. A slightly larger regenerator diameter of $0.2 \mathrm{~m}$ is chosen as the base case for the study. However, as the regenerator size is merely estimated by this analytical approach, several sensitivities on the effect of the regenerator size and geometry are run. These sensitivities are detailed in Table 3.

The heat exchanger channel width and height chosen are an approximate representation of those found in intercooler cores, the type of exchanger that is planned to be used on the experimental engine. This exchanger type consists of several smaller finned channels stacked on top of cross flow channels for the heat transfer fluid. An example image of an intercooler core is shown in Fig. 4. This heat exchanger type is represented as rectangular channel heat exchangers. The finned pathways divide the heat exchanger into several smaller rectangular channels that are heated from both sides by the heat transfer fluid with short conduction paths. The length of the heat exchanger channel is the length of the gas path through the heat exchanger and the number of channels corresponds to the frontal area. Different sized intercooler cores will have different lengths and different numbers of channels yielding different frontal areas, but the channel width and height are consistent.

It is important to note that the model does not include any volume associated with gas connection volumes in order to simplify the model setup. This includes volumes such as a plenum for distribution of the working fluid into the heat exchanger volume, or clearance spaces.

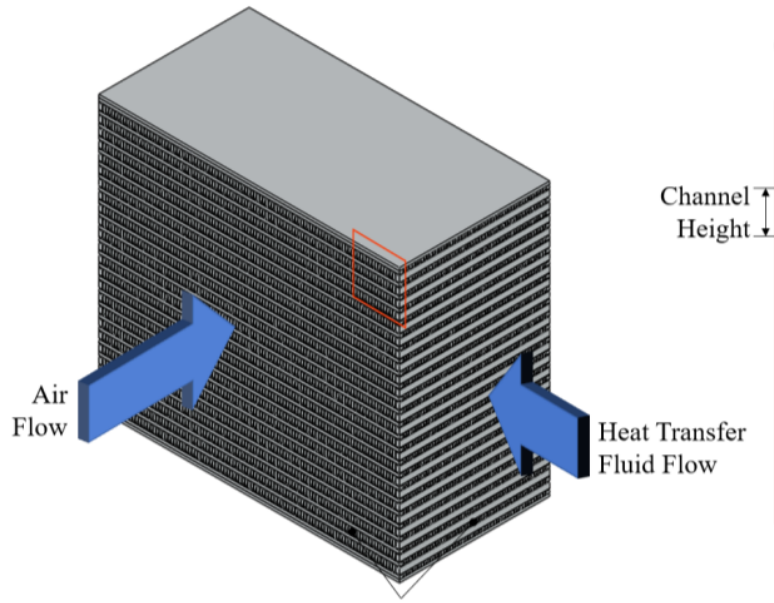

Channel Width

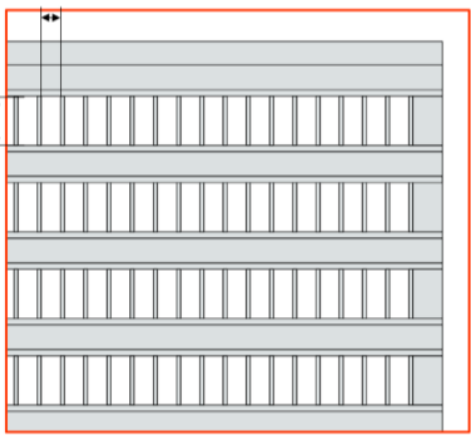

Finned Channels

Fig. 4. Sample intercooler core geometry showing channel geometry. 


\subsection{Defined Output Variables}

Four outputs from Sage are considered in this study:

- Power

- Average Gas Temperature Difference

- $\quad 1^{\text {st }}$ Order Expansion Space Pressure Swing

- $\quad 1^{\text {st }}$ Order Compression Space Pressure Swing

The output power is defined as the sum of the spatially integrated and temporally averaged power in the expansion and compression spaces as calculated by Sage. The average gas temperature difference is defined as the difference between the spatially and temporally averaged gas temperatures in the expansion and compression spaces. The pressure swing is the difference between the maximum and minimum pressure during the cycle. The pressure swing in both the expansion and compression space is taken from the Fourier series solution for pressure variation in the engine. This Fourier series is spatially averaged in each space, and only the first order amplitude is taken to approximate the pressure swing, as the remaining terms in the Fourier series have a diminishing effect on the value of pressure swing. The pressure swing amplitude is taken for both spaces as they are separated by the heat exchangers and regenerator, so the difference in pressure swing in the spaces is a result of the pressure drop across those components.

\section{Methodology}

For this study the heat exchanger channel length and number of channels were varied while the channel width and height were held constant. The variation of length and number of channels yields a variety of heat exchanger sizes from which an optimum heat exchanger volume and geometry can be determined. The range of heat exchanger channel lengths and number of channels considered is shown in Table 4, where the model is solved for every possible combination of these parameters.

Table 4. Variable engine properties.

\begin{tabular}{|c|c|c|c|}
\hline Engine Property & $\begin{array}{c}\text { Minimum } \\
\text { Value }\end{array}$ & $\begin{array}{c}\text { Maximum } \\
\text { Value }\end{array}$ & Increment \\
\hline Heat Exchanger Channel Length & $0.10 \mathrm{~m}$ & $0.50 \mathrm{~m}$ & $0.05 \mathrm{~m}$ \\
\hline Heat Exchanger Number of Channels & 2000 & 10000 & 1000 \\
\hline
\end{tabular}

The range of heat exchanger sizes considered in this study is first analysed based on the Schmidt model for Stirling engines, as described by Urieli and Berchowitz [15] and derived for Gamma type Stirling engines by Senft [4]. This is used to give a simple overview of the effect of dead volume as related to the size of the heat exchangers to engine power. Input into the Schmidt model are the volumes and assumed gas temperatures of the engine spaces. The heat exchanger volumes input into the Schmidt model were varied along with the assumed gas temperatures of the engine spaces. The lowest gas temperature difference assumed is based on experimental data showing the average hot side and cold side temperature of a lowtemperature Gamma type Stirling engine [10]. The highest gas temperature difference considered is equal to the source and sink temperatures.

The power output calculated by the Schmidt model is plotted against the dead volume ratio for a series of assumed gas temperature differences in Fig. 5. The dead volume ratio is defined by Senft [4] as the total engine dead volume divided by the displacer piston swept volume. It can be seen that the power output is higher for higher temperature differences for 
all dead volume ratios, with the power output decreasing with increased dead volume ratio. However, there is a point where the power output for a heat exchanger that provides average gas temperatures with zero dead volume is equivalent to that of a heat exchanger that achieves the source and sink temperatures with higher dead volume, as marked by the black crosshairs. These represent theoretical bounds on the optimum size of a heat exchanger, wherein an improvement in heat exchange resulting from an increase to the heat exchanger size will result in higher power output, as is the case in the top left quadrant formed by the crosshairs. In the bottom right quadrant, the power reduction due to dead volume is too great to overcome even for a perfect heat exchanger, so no heat exchanger volume optimum should exist in this quadrant.

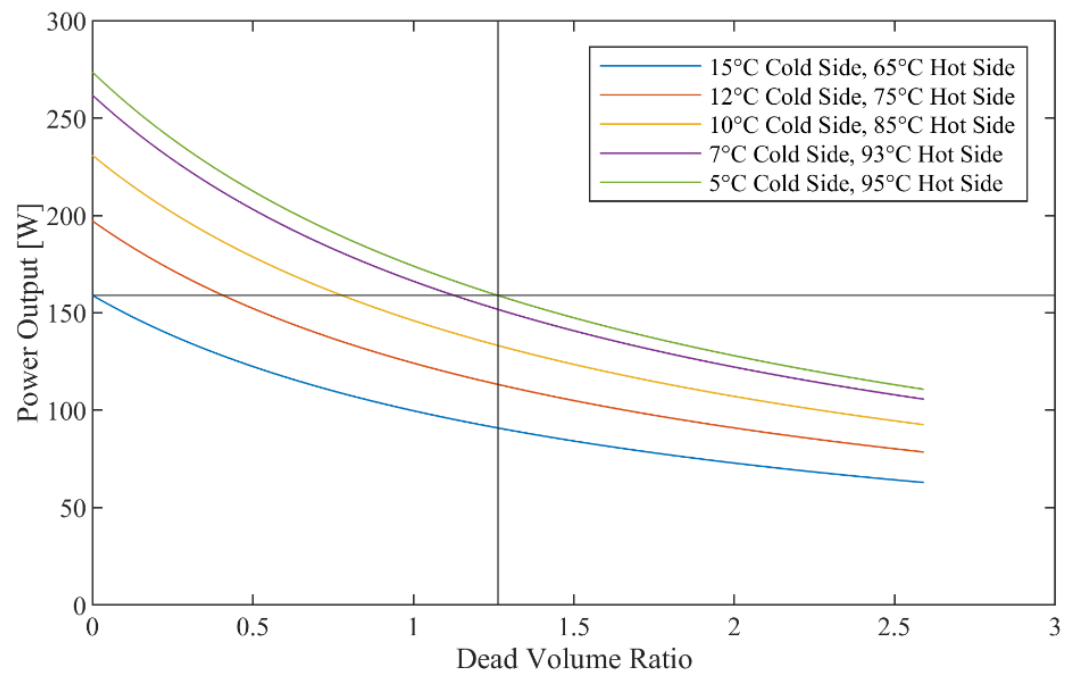

Fig. 5. Plot of power output as calculated by the Schmidt model against dead volume ratio for various assumed gas temperature differences.

The dead volume ratio range of the heat exchanger sizes must have a maximum bound of at least 1.26, assuming that the lowest achieved gas temperature difference is similar to that considered here. The largest heat exchanger size included has a dead volume ratio of 4.83 , which is much greater than 1.26 and will be able to account for any difference in the assumption of what the lowest achieved gas temperature differences are for the engine.

The lowest heat exchanger volume considered is limited by the practical implementation length requirements for the planned experimental engine, as well as the ability of the model to solve for a very small heat exchanger. Due to this, the lowest dead volume ratio considered was 0.34 .

\section{Results}

\subsection{Heat Exchanger Size}

The Sage model results for varying the heat exchanger volume and geometry in the base case show that there is an optimum heat exchanger volume for producing maximum power. In Fig. 6 the output power is plotted against dead volume ratio, where an increase in dead volume ratio corresponds to an increase in the frontal area. It can be seen that the maximum engine power of $44.3 \mathrm{~W}$ occurs for a heat exchanger length of $0.1 \mathrm{~m}$ with 7000 channels. This occurs at a dead volume ratio of 0.81 which is also within the maximum bound predicted 
by the Schmidt model. It can also be seen that the effect of excess dead volume is apparent by the decrease in engine power for high dead volume ratios, to the point where the engine power is negative.

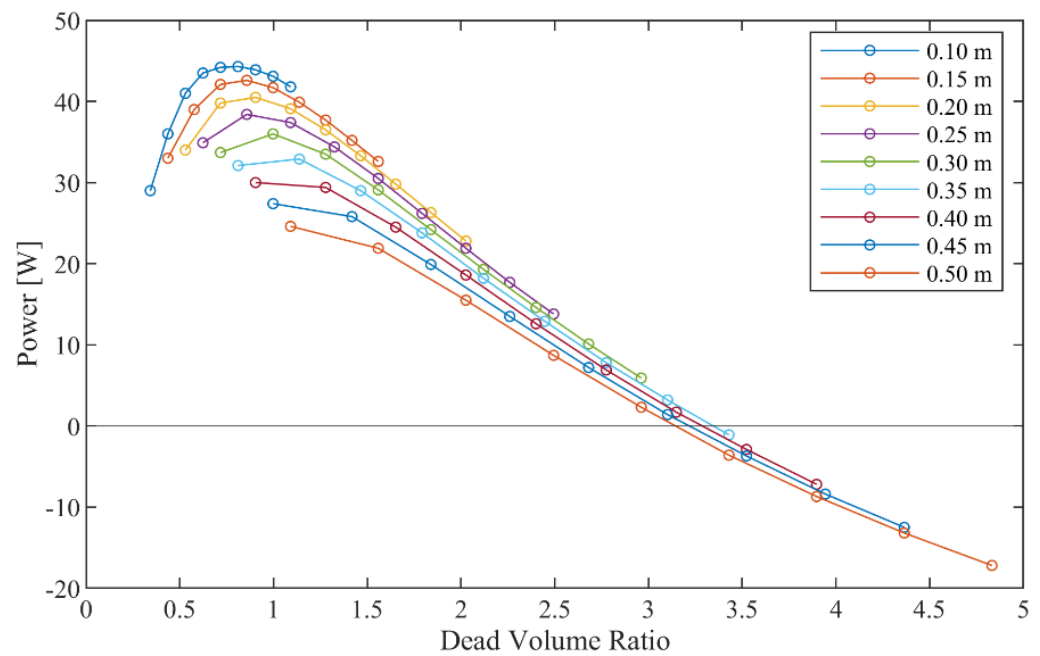

Fig. 6. Plot of power output from Sage against dead volume ratio for various heat exchanger lengths.

In Fig. 7 the average gas temperature difference increases with increasing dead volume ratio, which corresponds to increasing heat exchanger volume. This is expected as the maximum temperature difference that could be achieved is $90{ }^{\circ} \mathrm{C}$, so the temperature difference will approach that value asymptotically. All of the different heat exchanger volumes and geometries collapse onto the same curve with only slight variation. This is because the heat transfer is governed by the total surface area in contact with the working fluid. Thus, a long heat exchanger with small frontal area that has the same surface area as a short heat exchanger with a large frontal area, will produce the same temperature output at the exit.

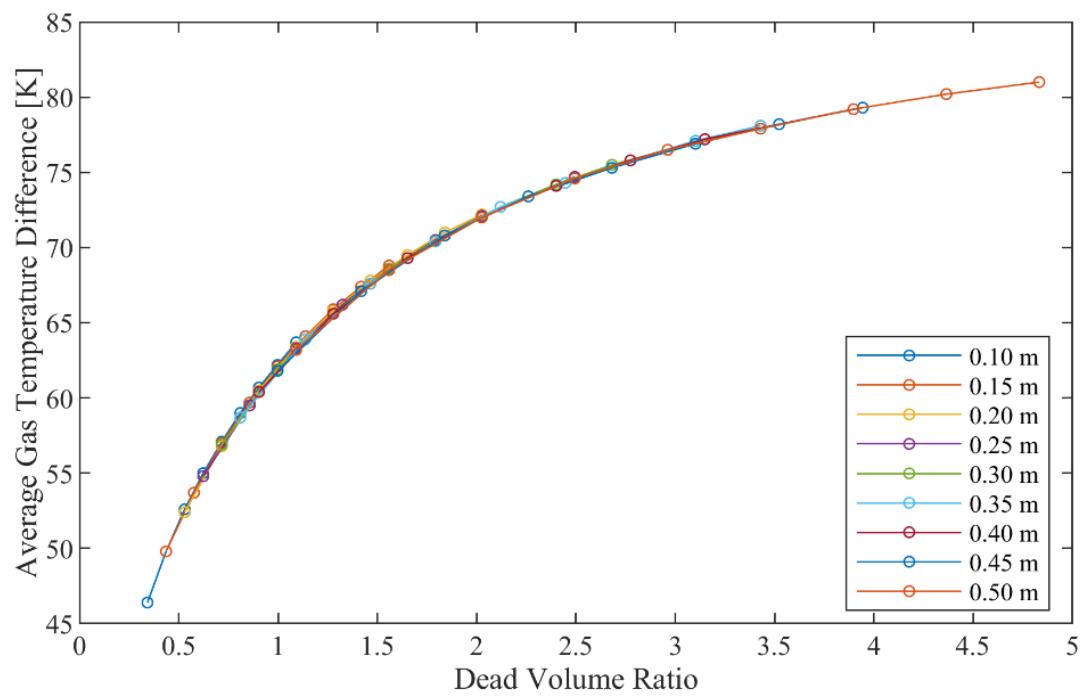

Fig. 7. Plot of average gas temperature difference against dead volume ratio for various heat exchanger lengths. 
In Fig. 8 the compression and expansion space pressure swings are plotted against the dead volume ratio, where it can be seen that the pressure swing in both spaces of the engine decreases significantly with increased dead volume ratio. This would contribute to the overall decrease in engine power despite the increased gas temperatures at the same dead volume ratio. As the expansion and compression spaces are separated by the heat exchangers and regenerator, the gap between these two spaces results from the pressure drop through these components.

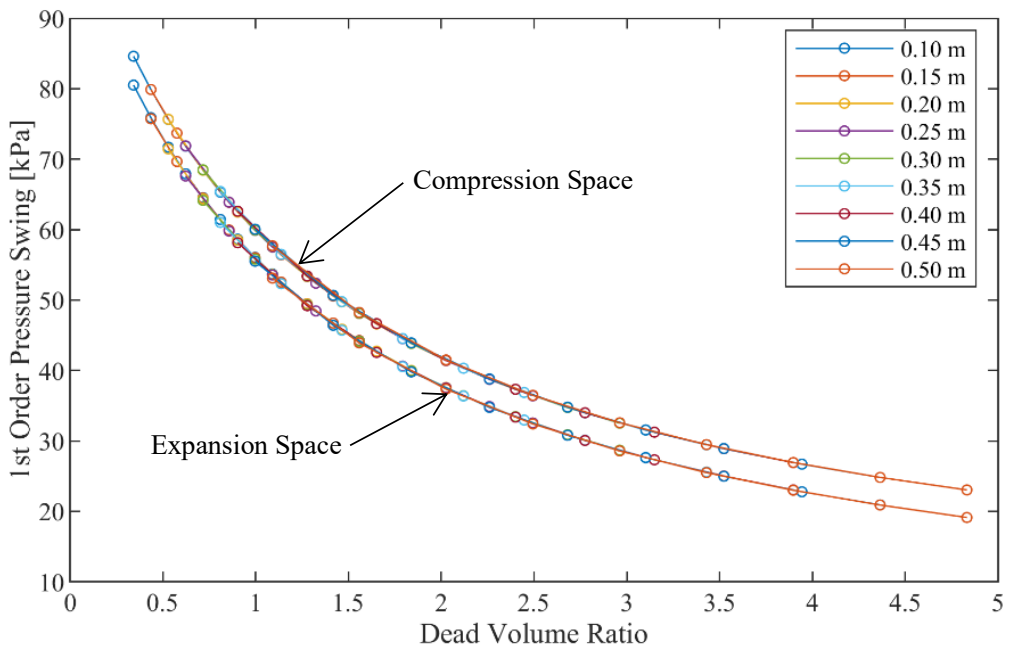

Fig. 8. Plot of $1^{\text {st }}$ order expansion and compression space pressure swings against dead volume ratio for various heat exchanger lengths.

As can be seen in Fig. 6, the shorter heat exchangers resulted in higher power output and optimum power output for the engine. This is a result of the effect of the pressure drop through the heat exchanger length reducing the pressure swing and thus the output power. Table 5 highlights the output variables for the optimum power case and a lower power case at the same dead volume ratio of 0.81 .

Table 5. Comparison of output variables between optimal power and low power cases at equivalent DV ratio of 0.81 .

\begin{tabular}{|c|c|c|}
\hline Properties & $\begin{array}{c}\text { Optimum Power } \\
\text { Case }\end{array}$ & $\begin{array}{c}\text { Low Power } \\
\text { Case }\end{array}$ \\
\hline Heat Exchanger Length & $0.10 \mathrm{~m}$ & $0.35 \mathrm{~m}$ \\
\hline Number of Heat Exchanger Channels & 7000 & 2000 \\
\hline Average Gas Temperature Difference & $59.0 \mathrm{~K}$ & $58.7 \mathrm{~K}$ \\
\hline $1^{\text {st }}$ Order Compression Space Pressure Swing & $65.32 \mathrm{kPa}$ & $65.42 \mathrm{kPa}$ \\
\hline $1^{\text {st }}$ Order Expansion Space Pressure Swing & $61.44 \mathrm{kPa}$ & $61.02 \mathrm{kPa}$ \\
\hline Power & $44.3 \mathrm{~W}$ & $32.1 \mathrm{~W}$ \\
\hline
\end{tabular}

It can be seen that the low power case has a lower expansion space pressure swing and a higher compression space power swing than the optimum case. Thus, the expansion space is doing less work while the compression space is having more work done on it, resulting in 
lower output power than the optimal case, with higher expansion space work and less work being done on the compression space. This indicates that the effect of pressure drop through the heat exchangers on engine power output is significant, and that shorter heat exchangers are favourable for low-temperature Stirling engines provided that they have sufficient surface area to achieve an acceptable gas temperature difference in the engine.

\subsection{Regenerator Sensitivity}

The results of the regenerator sensitivity indicate that the regenerator size itself has a large effect on power output of the engine, as can be seen in the heat map in Fig. 9. Pressure drop through the regenerator appears to have an impact, with the highest power being achieved for the shortest and largest diameter regenerator. The difference between the compression space pressure swing and the expansion space pressure swing for this high power case of $96.9 \mathrm{~W}$ is $1.12 \mathrm{kPa}$, smaller than the $3.88 \mathrm{kPa}$ in the base case. There may be additional influences resulting in this large power increase however, which are not apparent from the output variables and require further investigation. The optimum DV ratio does not show a discernible trend for varying regenerator sizes, with the value fluctuating from 0.69 to 0.83 . There is an impact of regenerator size on the heat exchanger DV fraction, which is defined as the volume of the heat exchanger divided by the total dead volume. The amount of heat exchanger volume is inversely proportional to the regenerator volume, with the overall dead volume amount not varying significantly. All of the heat exchangers that were optimal had channel lengths of $0.1 \mathrm{~m}$. When the regenerator is smaller, the heat exchanger size is increased by increasing the number of channels, and when the regenerator is very large the number of channels is decreased. This indicates that reduction in pressure drop of the heat exchangers is still important, as the shortest length is always the optimal case. However, the total surface area requirement for the heat exchangers, which is modified by changing the number of channels, is inversely related to the regenerator size.
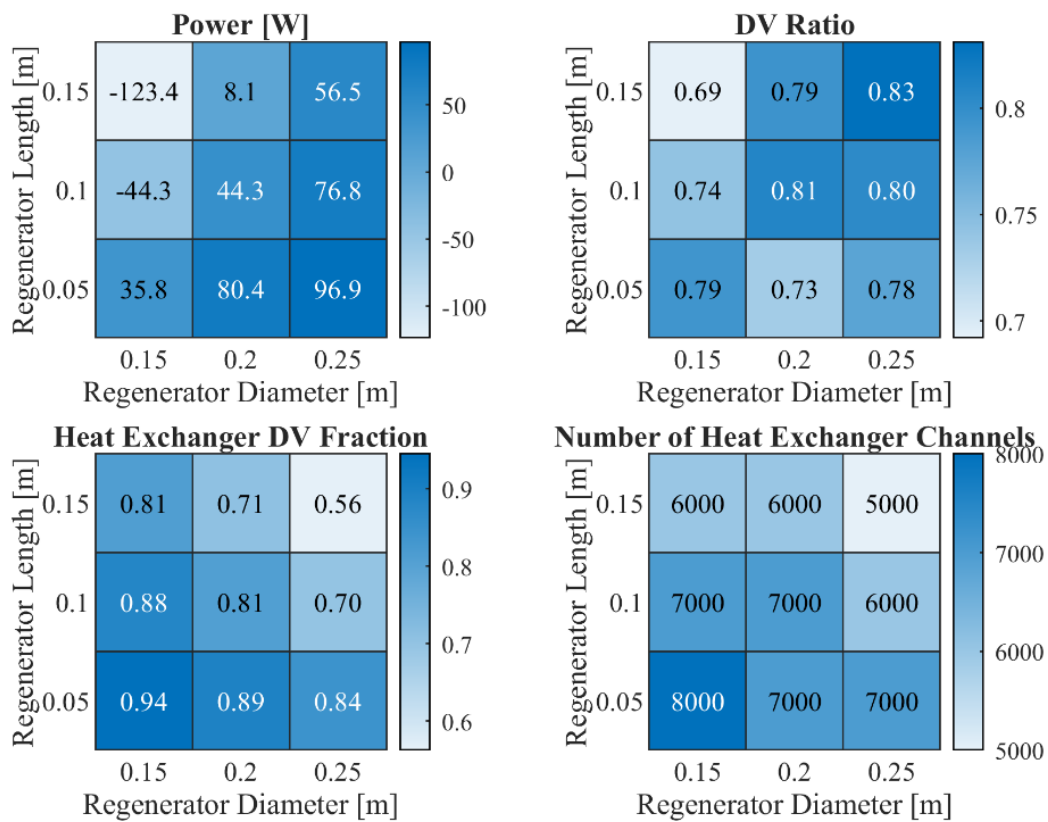

Fig. 9. Heat maps for optimum power, DV ratio, heat exchanger DV fraction, and number of heat exchanger channels for varying regenerator lengths and diameters. 


\subsection{Engine Speed Sensitivity}

The results of the engine speed sensitivity indicate that engine running speed has a significant effect on power output, as can be seen in Table 6. This is expected as a Stirling engine is capable of running at many different speeds. The lower speed has a slightly higher power output of $45.1 \mathrm{~W}$ than the base case, while the faster speed power output is much lower at - $155 \mathrm{~W}$, indicating that the engine would not be capable of running at this speed. This variation is likely due to the difference in pressure drop across the heat exchangers and regenerator resulting from the increase in flow friction at higher engine speeds. The difference in the pressure swing between the compression space and the expansion space varies from a low of $1.60 \mathrm{kPa}$ in the low speed case to a high $10.3 \mathrm{kPa}$ in the high speed case. The optimal heat exchanger geometries in each case are very similar, and produces similar gas temperature swings.

Table 6. Summary of output variables and optimum heat exchanger geometry from engine speed sensitivity.

\begin{tabular}{|c|c|c|c|}
\hline Output Variable & $\mathbf{0 . 5} \mathbf{~ H z}$ & $\mathbf{1 ~ H z}$ & $\mathbf{2 ~ H z}$ \\
\hline Optimum Engine Power & $45.1 \mathrm{~W}$ & $44.3 \mathrm{~W}$ & $-155 \mathrm{~W}$ \\
\hline Optimum Heat Exchanger Length & $0.10 \mathrm{~m}$ & $0.10 \mathrm{~m}$ & $0.10 \mathrm{~m}$ \\
\hline Optimum Number of Heat Exchanger Channels & 7000 & 7000 & 6000 \\
\hline Optimum DV Ratio & 0.81 & 0.81 & 0.72 \\
\hline $\begin{array}{c}\text { Difference in Pressure Swing between Expansion and } \\
\text { Compression Spaces }\end{array}$ & $1.60 \mathrm{kPa}$ & $3.88 \mathrm{kPa}$ & $10.3 \mathrm{kPa}$ \\
\hline \begin{tabular}{c} 
Average Gas Temperature Difference \\
\hline
\end{tabular} & $58.2 \mathrm{~K}$ & $59.0 \mathrm{~K}$ & $58.9 \mathrm{~K}$ \\
\hline
\end{tabular}

\section{Conclusion}

From the investigation of a low-temperature Stirling engine using a $3^{\text {rd }}$ order model it was determined that an optimum heat exchanger size and geometry exists which balances good heat transfer with dead volume penalties. The optimal heat exchanger for the engine studied had a length of $0.1 \mathrm{~m}, 7000$ channels, and a dead volume ratio of 0.81 . Shorter length heat exchangers were shown to be preferable as a result of the effect of pressure drop through the heat exchangers, provided that they contain sufficient heat transfer surface area to provide an adequate gas temperature difference in the engine. It was seen that the regenerator geometry follows a similar trend as for the heat exchanger geometry, wherein a shorter regenerator had a higher power output due to the decreased pressure drop. Additionally, the regenerator volume influenced with the optimal heat exchanger volume, with the two being inversely related. It was also seen that lower engine speeds resulted in higher power output, likely due to the decreased flow friction and pressure drop at lower speeds. This information and methodology can provide guidance in the selection of heat exchanger volume and geometry for experimental engines to optimize for power output, particularly in the case of lowtemperature Stirling engines where there is limited power available to overcome losses.

The authors acknowledge the financial support from Future Energy Systems (FES) from the University of Alberta, the Natural Sciences and Engineering Research Council of Canada (NSERC), and Alberta Innovates. 


\section{References}

1. J. Banks, "Deep-Dive Analysis of the Best Geothermal Reservoirs for Commercial Development in Alberta : Final Report," University of Alberta, Edmonton (2017)

2. "Community Integrated Energy Mapping Feasability Study in Alberta's Industrial Heartland and Strathcona Industrial Area" (2014). Available: http://cmcghg.com/wpcontent/uploads/2015/03/EEBE-062-Report-Short-EN.pdf

3. I. Kolin, Stirling Motor: History - Theory - Practice (Zagreb University Publications, Ltd., Dubrovnik, 1991).

4. J. Senft, Mechanical Efficiency of Heat Engines (Cambridge University Press, Cambridge, 2007)

5. W. Martini, Stirling Engine Design Manual, 2nd ed. (1983)

6. D. Gedeon, "Sage: Object Oriented Software for Stirling Machine Design," Proceedings of the Intersociety Energy Conversion Engineering Conf., USA, pp. 1902-1907 (1994)

7. R. Demko and L. Penswick, "Sage Simulation Model for Technology Demonstration Convertor by a Step-by-Step Approach," 3rd Int. Energy Conversion Engineering Conference (2005)

8. B. Hoegel, D. Pons, M. Gschwendtner, A. Tucker and M. Sellier, "Thermodynamic peculiarities of alpha-type Stirling engines for low-temperature difference power generation: Optimisation of operating parameters and heat exchangers using a thirdorder model," Proceedings of the Institution of Mechanical Engineering, Part C: Journal of Mech. Engineering Science, 228, no. 11, pp. 1935-1947 (2014)

9. "Canadian Climate Normals 1981-2010 Station Data," (Government of Canada, December 10, 2020) [Online]. Available: https://climate.weather.gc.ca/climate_normals/results_1981_2010_e.html?searchType= stnProv\&lstProvince $=\mathrm{AB} \& \mathrm{txtCentralLatMin}=0 \&$ txtCentralLatSec $=0 \&$ txtCentralLong Min $=0 \&$ txtCentralLongSec $=0 \& \operatorname{stnID}=1865 \&$ dispBack $=0$

10. C. Stumpf, "Parameter Optimization of a Low Temperature Difference Gamma-Type Stirling Engine to Maximize Shaft Power," Thesis (2019)

11. J. Senft, "Optimum Stirling engine geometry," Int. J. of Energy Research, 26, no. 12, pp. 1087-1101 (2002)

12. J. Egas, "Stirling Engine Configuration Selection," Energies, 11, no. 584, pp. 1-23 (2018)

13. R. Gheith, F. Aloui and S. Nasrallah, "Determination of adequate regenerator for a Gamma-type Stirling engine," Applied Energy, vol. 139, pp. 272-280, February 1, 2015.

14. "Steel Wool Grades," Engineering Toolbox (2010) [Online]. Available: https://www.engineeringtoolbox.com/steel-wool-grades-d 1619.html

15. I. Urieli and D. Berchowitz, Stirling Cycle Engine Analysis (Adam Hilger Ltd, Bristol, 1984) 